\title{
Public awareness of blood donation in Central Saudi Arabia
}

This article was published in the following Dove Press journal:

International Journal of General Medicine

12 August 2014

Number of times this article has been viewed

\author{
Mostafa A Abolfotouh ${ }^{1,2}$ \\ Mohammed H Al-Assiri' \\ Manar Al-Omani² \\ Alwaleed Al Johar ${ }^{3}$ \\ Abdulaziz Al Hakbani ${ }^{3}$ \\ Ahmed S Alaskar ${ }^{1,2}$ \\ 'King Abdullah International Medical \\ Research Center, ${ }^{2}$ King Saud bin- \\ Abdulaziz University for Health \\ Sciences, ${ }^{3}$ College of Medicine, \\ King Saud University, Riyadh, \\ Saudi Arabia
}

Introduction: In Saudi Arabia, voluntary donors are the only source of blood donation. The aim of this study was to assess the level of public knowledge and attitude toward blood donation in Saudi Arabia.

Methods: Using a previously validated questionnaire that comprises 38 questions to assess the levels of knowledge, attitudes, and motivations towards blood donation, 469 Saudi adults who attended different shopping malls in Riyadh, Saudi Arabia were surveyed. Multiple regression analyses were used to identify the significant predictors of blood donation, with the significance set at $P<0.05$.

Results: Approximately half of all subjects (53.3\%) reported that they had previously donated blood, $39 \%$ of whom had donated more than once. The knowledge percentage mean score was $58.07 \%$, denoting a poor level of knowledge, with only $11.9 \%$ reporting a good level of knowledge. The attitude percentage mean score towards donation was $75.45 \%$, reflecting a neutral attitude towards donating blood, with 31.6\% reporting a positive attitude. Donation was significantly more prevalent among males than females (66\% versus $13.3 \% ; P<0.001)$. After adjustment for confounders, a higher knowledge score $(t=2.59 ; P=0.01)$, a higher attitude score $(t=3.26 ; P=0.001)$, and male sex $(t=10.45 ; P<0.001)$ were significant predictors of blood donation. An inability to reach the blood donation centers and a fear of anemia were the main reasons for females not donating blood ( $49.9 \%$ and $35.7 \%$, respectively), whereas a lack of time was the main reason for males $(59.5 \%)$.

Conclusion: Prevalence of blood donation was less than satisfactory among the Saudi public, probably due to misconceptions, poor knowledge, and unfavorable attitude to donation. Educational programs are necessary to increase the level of knowledge and improve the attitude of the Saudi public toward blood donation. Providing mobile blood collection units nearer to individuals' places of work to reduce their time costs of donating is a necessity.

Keywords: knowledge, attitude, practice, blood donation, significant predictors, Saudi Arabia

\section{Introduction}

Blood is a major vital component of the human body. Since it cannot be manufactured artificially, and can only be obtained from human resources, ${ }^{1}$ blood donation has become an important and essential process that every health care facility should take into consideration. ${ }^{2}$ Recently, both developing and developed countries are finding it hard to recruit regular donors to donate six times per year. ${ }^{3,4}$ Blood donors are differentiated into: voluntary, family replacement, and remunerated or paid donors. ${ }^{5}$ Due to the increased number of blood borne infections caught from paid donors, ${ }^{6,7}$ developing and developed countries are trying to obtain blood from voluntary donors only. Confining the blood donor population to voluntary donors only, which is the World Health
Correspondence: Mostafa A Abolfotouh King Abdullah International Medical Research Center, PO Box 22490 , Riyadh I 1426, Saudi Arabia Tel +966 II 80 I IIII ext I4469 Fax +966 II 8043050

Email mabolfotouh@gmail.com submit your manuscript | www.dovepress.com

Dovepress

http://dx.doi.org// 0.2147//1]GM.S67/87
International Journal of General Medicine 20I4:7 40I-4I0

(c) (i) (5) 2014 Abolfotouh et al. This work is published by Dove Medical Press Limited, and licensed under Creative Commons Attribution - Non Commercial (unported, v3.0) BY NC License. The full terms of the License are available at http://creativecommons.org/licenses/by-nc/3.0/. Non-commercial uses of the work are permitted without any further pernisson from Dor Medcal Press Limited, provided the work is properly attributed. Pe how to request permission may be found at. http://www.dovepress.com/permissions.php 
Organization's instructions on blood donation, ${ }^{8}$ is not an easy task, as identified in previous studies. ${ }^{2,4,9}$ Mascaretti et al reported that only five out of 17 European countries accept blood from voluntary donors. ${ }^{10}$

Blood donation criteria was recently tightened for the sake of blood quality and safety, which resulted in a severe shortage of blood storage in the blood banks. ${ }^{11,12}$ What makes it more challenging is the increased demand for blood due to more advanced surgical techniques, a dramatic increase in the number of trauma patients, and new modalities in cancer treatment. ${ }^{13,14}$ A recent survey conducted in the US showed a spectacular increase in the demand for blood transfusions in 10 years: 1.1 million transfusions in 1997 against 2.7 million in 2007..$^{15}$

Several factors play a role in the recruitment and willingness of people to donate blood voluntarily. Various studies have revealed a significant association between the donor population and their demographic data ${ }^{13,14,16}$ in terms of sex, age, and level of education. With regards to knowledge of blood donation, studies have shown that the more knowledgeable a subject is about blood and the need for it, the more likely they are to be a previous donor. ${ }^{17,18}$ Investigators in different study settings had similar responses from subjects, who identified the number one reason behind their willingness to donate was being aware of blood needs among patients. ${ }^{2,16,19,20}$

The attitudes towards blood donation differ between donors and non-donors. Altruism is the major and most commonly reported reason motivating a subject to donate. ${ }^{14}$ Religious act, national duty, quality of service at the blood bank, and family needs or encouragement were all positive attitudes associated with one's decision to donate. ${ }^{14,21}$ On the other hand, there were negative attitudes that were reported from non-donors, fear being the most commonly

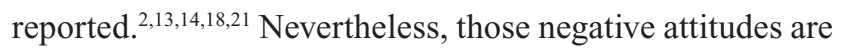
not all true, as the population suffers from rooted misconceptions that need to be corrected. Physical weakness, age limitations, high risk of infections, and blood being sold to patients, are incorrect beliefs existing among the public. ${ }^{3,22,23}$ Correction of these misconceptions is essential; the media, especially television, should be utilized in this situation since it is the number one source of information in some communities. ${ }^{14}$

In Saudi Arabia, non-remunerated, voluntary blood donors are the only source of blood donation. A previous local study conducted by Abdel Gader et al showed a strong positive attitude towards blood donation. ${ }^{21}$ However, after a recent incident of human immunodeficiency virus
(HIV)/acquired immunodeficiency syndrome transmission to a young Saudi girl following blood transfusion, ${ }^{24}$ the perception of the Saudi public towards blood donation has possibly changed. The aims of the current study were to 1) assess the level of Saudi public knowledge and attitude towards blood donation and 2) describe previous experiences and barriers to blood donation. Elaboration of the strategies that motivate people to donate blood could lead to the maintenance of a sufficient blood source.

\section{Methods}

\section{Study subjects}

Adults over the age of 18 years (both male and female) in shopping malls in the city of Riyadh (the capital city of Saudi Arabia), who provided verbal consent, were eligible to participate in the survey. Non-Saudi subjects and those not willing to participate were excluded.

\section{Study design}

A cross-sectional study design was used.

\section{Study population and sampling technique}

Based on a previous study that showed $26 \%$ of the subjects exhibited a positive attitude towards blood donation, ${ }^{14}$ with a margin of error of $4 \%$, and a $95 \%$ confidence interval, the estimated required sample size was 464 . A number of large malls that serve different geographical areas of Riyadh were identified. Proportional quota sampling was used to ensure that respondents were demographically representative of the general population with quotas based on age, sex, work status, region, and social class. Adults shopping in these malls within the 2 weeks between 8-22 July, 2013, who were willing to participate in the study were interviewed. Each data collector spent an average of 3 hours in each mall, at randomly chosen times of the day to recruit participants. A total of 469 subjects (including both sexes) were successfully interviewed.

\section{Data collection methods}

The study was based on an interview questionnaire. The questionnaire was initially designed by the research team according to a previously validated questionnaire. ${ }^{14}$ The interview questionnaire was translated into Arabic. The test-retest reliability was measured in a pilot study of ten participants. Discussions with various relevant experts at King Abdullah International Medical Research Center (Riyadh, Saudi Arabia) confirmed the content validity and feasibility of the questionnaire to ensure the relevance and 
clarity of the questions. Several additions and amendments were made to ensure that the questions were valid in a Saudi context. The questionnaire sheet consisted of 38 questions, divided into four parts:

- The first part collected sociodemographic data of the participant, such as age, sex, marital status, and educational level. It also assessed participant's background and their sources of information regarding blood donation.

- The second part assessed the participant's level of knowledge regarding blood donation. This part consisted of a total of eleven statements. These statements included if there is an age limitation on blood donation, if people of any blood group can donate, and if women can donate when menstruating. Other statements asked about the possibility of certain consequences (eg, anemia and transmission of infection to donor or receiver) following blood donation. In addition, the participants, awareness of preventive conditions for blood donation were examined. These conditions were listed as a history of drug abuse or an unsafe sexual relationship, a diagnosis of anemia, diabetes, hypertension, or pregnancy. Furthermore, it asked if laboratories tested donated blood for HIV, hepatitis, and syphilis, and if there is a sex preference for blood donation. Each question was rated zero for a wrong answer and one for the right answer. An overall knowledge score was then calculated by adding the scores for the statements. Thus, the highest possible score was eleven points. Percentage mean scores (PMS) were calculated and the level of knowledge was classified as "good" (>80\%), "average" (60\%-80\%) and "poor" (<60\%).

- The third part assessed attitudes toward blood donation. This part included ten attitude statements to be answered using a five-point Likert scale. The statements were regarding the participants' beliefs and perceptions about blood donation. Participants gave "strongly agree", "agree", "not sure", "disagree", or "strongly disagree" responses to all of the questions.

Negative attitude statements were scored from five (for participants who strongly agreed) to one (for participants who strongly disagreed). The opposite of this scoring system was used for the positive attitude statements. Accordingly, the total attitude score ranged between eleven and 55 points. PMS were calculated. Levels of attitude were classified as: "positive" (>80\%), "neutral" (60\%-80\%), and "negative" (<60\%).

- The fourth part asked whether the participant had ever donated blood or not, the frequency of donation, and reasons for not donating blood.

\section{Ethical considerations}

Participation in the study was voluntary, and each participant was able to withdraw from the study at any time. The investigators explained the aim of the study to the participants. The study protocol received ethical approval from the Saudi National Guard Health Affairs (Riyadh, Saudi Arabia) (application number RR 013/44).

\section{Data analysis}

Data entry and statistical analysis were performed using SPSS $^{\circledR}$ version 20.0 (IBM Corporation, Armonk, NY, USA). Descriptive statistics, such as percentages, frequencies, means, and standard deviations, were used to measure the demographic variables and the responses to knowledge and attitude statements. Analytical statistics were applied to investigate the association of knowledge and attitude with demographic variables. Multiple linear regression analyses were performed to identify the significant predictors for frequency of blood donation. Statistical significance was set at $P<0.05$ for all analyses.

\section{Results}

The study sample comprised $75.9 \%$ men and $24.1 \%$ women. A total of $48.8 \%$ were under 30 years old, $54.6 \%$ of participants' level of education was below university level, and 58.8\% were currently married. More than half of all participants $(53.3 \%)$ reported a previous history of blood donation, $66 \%$ of whom were males and only $13.3 \%$ females $\left(\chi^{2}=95.84, P<0.001\right)$. Frequency of donation ranged between $1-38$ times, with an average frequency of $2.61 \pm 4.72$ times. This average was significantly higher in males $(3.37 \pm 5.18)$ than in females $(0.20 \pm 0.64 ; t=11.26$; $P<0.001)$. Repeat donors constituted $39.3 \%$ of all participants (50.3\% males; $4.4 \%$ females). Previous blood transfusion to one of the family members and/or a relative was reported by $35.2 \%$ of all participants $(30.6 \%$ males; 49.6\% females; $\chi^{2}=13.49 ; P<0.001$ ) (Table 1 ).

Figure 1 shows the reasons provided for not donating blood, divided by sex. Lack of time ranked first as the reason for not donating $(52.5 \%)$, followed by inability to access the blood bank for donation (33.8\%), family discouragement (28.8\%), fear of anemia (21.9\%) fear of infection (14.6\%), fear of the needle (11.9\%), and lastly, fear of the sight of blood $(8.2 \%)$. A lack of time was reported at a significantly higher frequency by males $\left(\chi^{2}=5.30 ; P=0.021\right)$, whereas a significantly higher number of females reported an inability to reach the blood bank $\left(\chi^{2}=11.66 ; P=0.001\right)$, and fear of anemia $\left(\chi^{2}=19.73 ; P<0.001\right)$. 
Table I Personal characteristics and donation-related characteristics

\begin{tabular}{|c|c|c|c|c|c|c|}
\hline & \multicolumn{2}{|c|}{ Male $(\mathrm{N}=356)$} & \multicolumn{2}{|c|}{ Female $(\mathrm{N}=|| 3)$} & \multicolumn{2}{|c|}{ Total $(\mathrm{N}=469)$} \\
\hline & $\mathbf{n}$ & $\%$ & $\mathbf{n}$ & $\%$ & $\mathbf{n}$ & $\%$ \\
\hline \multicolumn{7}{|l|}{ Age group } \\
\hline$<30$ years & 172 & 48.3 & 57 & 50.2 & 229 & 48.8 \\
\hline \multirow[t]{2}{*}{$\geq 30$ years } & 184 & 51.7 & 56 & 49.6 & 240 & 51.2 \\
\hline & $\chi^{2}=0.155 ; P=$ & & & & & \\
\hline \multicolumn{7}{|l|}{ Education level } \\
\hline$\leq$ High school & 209 & 58.7 & 47 & 41.6 & 256 & 54.6 \\
\hline \multirow[t]{2}{*}{ University } & 147 & 41.3 & 66 & 85.4 & 213 & 45.4 \\
\hline & $\chi^{2}=10.135 ; P=$ & & & & & \\
\hline \multicolumn{7}{|l|}{ Marital status } \\
\hline Married & 202 & 56.7 & 74 & 65.5 & 276 & 58.8 \\
\hline \multirow[t]{2}{*}{ Unmarried } & 154 & 43.3 & 36 & 34.5 & 193 & 41.2 \\
\hline & $\chi^{2}=2.709 ; P=$ & & & & & \\
\hline \multicolumn{7}{|l|}{ Previous donation } \\
\hline None & 121 & 34.0 & 98 & 86.7 & 219 & 46.7 \\
\hline Once & 56 & 15.7 & 10 & 8.8 & 66 & 14.1 \\
\hline $2-4$ times & 89 & 25.0 & 4 & 3.5 & 93 & 19.8 \\
\hline \multirow{2}{*}{$\geq 5$ times } & 90 & 25.3 & 1 & 0.9 & 91 & 19.4 \\
\hline & $\chi^{2}=100.204$ & & & & & \\
\hline \multicolumn{7}{|c|}{ Previous blood transfusion } \\
\hline Yes & 109 & 30.6 & 56 & 49.6 & 165 & 35.2 \\
\hline \multirow[t]{2}{*}{ No } & 247 & 69.4 & 57 & 50.4 & 304 & 64.8 \\
\hline & $\chi^{2}=13.49 ; P<$ & & & & & \\
\hline \multirow{2}{*}{ Mean \pm SD } & $32.24 \pm 11.57$ & & $31.11 \pm 8.82$ & & $31.97 \pm 10.98$ & \\
\hline & & & & & $t=1.10, P=0.2$ & \\
\hline
\end{tabular}

Notes: *Statistically significant. $\mathrm{N}$ denotes the total number of males, females and both; $\mathrm{n}$ denotes the number of each category in different variables. Abbreviation: SD, standard deviation.

Table 2 shows the levels of knowledge and attitude of the Saudi public toward blood donation by sex. It shows that about half $(48.0 \%)$ of the study sample had a poor level of knowledge, with only $11.9 \%$ having a good level knowledge on blood donation, with no significant sex difference $\left(\chi^{2}=3.48 ; P=0.175\right)$. The level of attitude towards blood donation was neutral for the majority of subjects $(61.6 \%)$, with $31.6 \%$ reporting a positive attitude and only $6.8 \%$ reporting a negative attitude. Participants with a positive attitude constituted $36.2 \%$ of all males compared to only $16.8 \%$ of all females $\left(\chi^{2}=15.34 ; P<0.001\right)$.

Table 3 shows the responses to the knowledge statements on blood donation. The majority of participants correctly identified that those with history of drug abuse (67\%), illegal

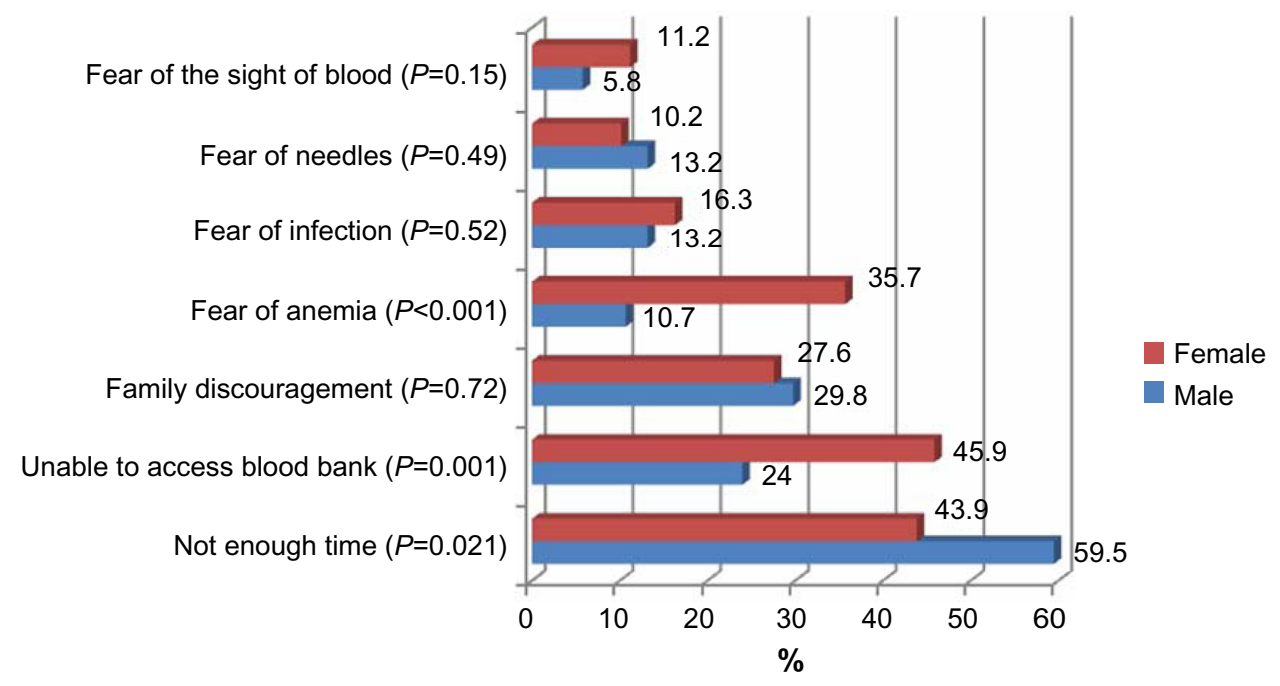

Figure I Reasons for not donating among the Saudi public by sex. 
Table 2 Levels of knowledge and attitude of the Saudi public in regards to blood donation by sex

\begin{tabular}{|c|c|c|c|c|c|c|c|c|c|c|c|c|}
\hline \multirow[t]{3}{*}{ Sex } & \multicolumn{6}{|c|}{ Knowledge level } & \multicolumn{6}{|c|}{ Attitude level } \\
\hline & \multicolumn{2}{|c|}{ Good } & \multicolumn{2}{|c|}{ Average } & \multicolumn{2}{|c|}{ Poor } & \multicolumn{2}{|c|}{ Positive } & \multicolumn{2}{|c|}{ Neutral } & \multicolumn{2}{|c|}{ Negative } \\
\hline & $n$ & $\%$ & $\mathbf{n}$ & $\%$ & $\mathbf{n}$ & $\%$ & $\mathbf{n}$ & $\%$ & $\mathbf{n}$ & $\%$ & $n$ & $\%$ \\
\hline Male & 39 & 11.0 & 138 & 38.7 & 179 & 50.3 & 129 & 36.2 & 203 & 57.0 & 24 & 6.8 \\
\hline Female & 17 & 15.0 & 50 & 44.2 & 46 & 40.8 & 19 & 16.8 & 86 & 76.1 & 8 & 7.1 \\
\hline \multirow[t]{2}{*}{ Total } & 56 & 11.9 & 188 & 40.1 & 225 & 48.0 & 148 & 31.6 & 289 & 61.6 & 32 & 6.8 \\
\hline & \multicolumn{6}{|c|}{$\chi^{2}=3.48 ; P=0.175$} & \multicolumn{6}{|c|}{$\chi^{2}=15.34 ; P<0.00 I^{*}$} \\
\hline
\end{tabular}

Note: *Statistically significant $P$-value.

sexual relations $(72.5 \%)$, or those with diabetes, hypertension, and/or anemia (75.7\%) are not allowed to donate blood. The majority correctly reported that blood donation could cause transmission of infection to the receiver $(73.8 \%)$, but only $22.8 \%$ correctly reported the possibility of transmission to the donor. About half (68\%) correctly reported that people with any blood group can donate blood, yet only one-third correctly reported that age (39.2\%) and menstruation (33.7\%) are not considered as limitations for donation.

Table 4 shows the responses to attitude statements towards blood donation. Almost all participants (96\%) agreed that donation is altruistic, and the majority disagreed with donation if the person donating is receiving leave from work $(75.1 \%)$ or incentives $(92.7 \%)$. The majority agreed that donation is a national duty $(82.6 \%)$ and that when they donate blood they feel they are donating to a family member or a friend $(91.9 \%)$, and $70 \%$ agreed that their families consider donation a valuable act and encourage them to donate. However, $34.1 \%$ agreed that they would only donate blood if they were sure that the donation will be given to them or their family members in the future. Those who considered donation a religious duty constituted $58.7 \%$ of all participants.

Table 5 shows the association between knowledge and attitude PMS for blood donation with some sociodemographic and blood donation characteristics. PMS of knowledge was significantly higher in male participants $(t=2.68$; $P=0.008)$ of a higher education $(t=3.32 ; P=0.001)$, who were married $(t=2.11 ; P=0.036)$, and who had reported previous experience with blood transfusion $(t=2.86 ; P=0.004)$. After adjustment for potential confounders, this association was significant only for education level $(P=0.001)$ and previous experience with blood transfusion $(P=0.021)$. Further, PMS for attitude was significantly higher for males $(76.45 \pm 12.12)$ than for females $(72.32 \pm 9.69 ; t=3.70 ; P<0.001)$. This sex difference in attitude PMS remained significant $(P=0.001)$ after adjusting for all other confounding variables. A positive and direct relationship between attitude and awareness PMS was shown in this study $(r=0.301 ; P<0.001)$.

Figure 2 shows that participants with a previous history of blood donation had significantly higher PMS for knowledge

Table 3 Response to knowledge statements about blood donation

\begin{tabular}{|c|c|c|c|c|c|c|c|}
\hline \multirow[t]{2}{*}{ Knowledge } & \multicolumn{2}{|l|}{ Yes } & \multicolumn{2}{|l|}{ No } & \multicolumn{2}{|c|}{ Do not know } & \multirow[t]{2}{*}{ Sex difference } \\
\hline & $\mathbf{n}$ & $\%$ & $\mathbf{n}$ & $\%$ & $\mathbf{n}$ & $\%$ & \\
\hline Is there any age limitation on blood donation? & 184 & $39.2^{\#}$ & $|5|$ & 32.2 & 134 & 28.6 & $7.84(P=0.02)^{*}$ \\
\hline Can women donate blood while menstruating? & 158 & $33.7^{\#}$ & 143 & 30.5 & 168 & 35.8 & $100.76(P<0.01)^{*}$ \\
\hline Can people with any blood group donate blood? & 319 & $68.0^{\#}$ & 73 & 15.6 & 77 & 16.4 & $3.007(P=0.22)$ \\
\hline Does blood donation cause anemia? & 39 & 8.3 & 339 & $72.3^{\#}$ & 91 & 19.4 & $2.37(P=0.31)$ \\
\hline $\begin{array}{l}\text { Could blood donation cause transmission of infection } \\
\text { to the donor? }\end{array}$ & 107 & $22.8^{\#}$ & 307 & 65.5 & 55 & 11.7 & $0.2(P=0.91)$ \\
\hline $\begin{array}{l}\text { Could blood donation cause transmission of infection } \\
\text { to the receiver? }\end{array}$ & 346 & $73.8^{\#}$ & 77 & 16.4 & 46 & 9.8 & $7.49(P=0.02)^{*}$ \\
\hline $\begin{array}{l}\text { Is someone with a history of drug abuse allowed to } \\
\text { donate blood? }\end{array}$ & 33 & 7.0 & 314 & $67.0^{\#}$ & 122 & 26.0 & $2.727(P=0.26)$ \\
\hline $\begin{array}{l}\text { Is someone with a history of an unsafe sexual relationship } \\
\text { allowed to donate blood? }\end{array}$ & 49 & 10.4 & 340 & $72.5^{\#}$ & 80 & 17.1 & $4.217(P=0.12)$ \\
\hline $\begin{array}{l}\text { Are anemic, diabetic, or hypertensive people or pregnant } \\
\text { ladies allowed to donate blood? }\end{array}$ & 31 & 6.6 & 355 & $75.7^{\#}$ & 83 & 17.7 & $0.578(P=0.75)$ \\
\hline $\begin{array}{l}\text { Does the laboratory test donated blood for HIV, hepatitis, } \\
\text { and syphilis? }\end{array}$ & 369 & $78.7^{\#}$ & 32 & 6.8 & 68 & 14.5 & $20.13(P<0.01)^{*}$ \\
\hline
\end{tabular}

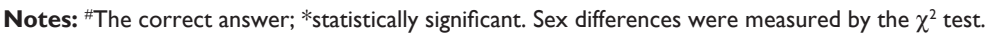
Abbreviation: HIV, human immunodeficiency virus. 
Table 4 Response to attitude statements about blood donation

\begin{tabular}{|c|c|c|c|c|c|c|c|c|c|c|c|}
\hline \multirow[t]{2}{*}{ Attitude } & \multicolumn{2}{|c|}{$\begin{array}{l}\text { Strongly } \\
\text { agree }\end{array}$} & \multicolumn{2}{|c|}{ Agree } & \multicolumn{2}{|c|}{ Neutral } & \multicolumn{2}{|c|}{ Disagree } & \multicolumn{2}{|c|}{$\begin{array}{l}\text { Strongly } \\
\text { disagree }\end{array}$} & \multirow[t]{2}{*}{ Sex difference } \\
\hline & n & $\%$ & $\mathbf{n}$ & $\%$ & $\mathbf{n}$ & $\%$ & n & $\%$ & $\mathbf{n}$ & $\%$ & \\
\hline I think that blood donation is altruistic & 338 & 72. $1^{\#}$ & 112 & $23.9^{\#}$ & 9 & 1.9 & 9 & 1.9 & I & 0.2 & $4.01(P=0.4)$ \\
\hline $\begin{array}{l}\text { I do not think that my donation will encourage } \\
\text { others to donate }\end{array}$ & 21 & 4.5 & 70 & 14.9 & 76 & 16.2 & 162 & $34.5^{\#}$ & 140 & $29.9^{\#}$ & $27.4(P<0.001)^{*}$ \\
\hline $\begin{array}{l}\text { I would donate blood if I was assured that the } \\
\text { donated blood will be given to me or to one } \\
\text { of my family in the future }\end{array}$ & 83 & 17.7 & 77 & 16.4 & 34 & 7.2 & 187 & $39.9^{\#}$ & 88 & $18.8^{\#}$ & $7.78(P=0.1)$ \\
\hline $\begin{array}{l}\text { My family and friends consider blood donation } \\
\text { as an important valuable act and encourage me } \\
\text { to donate }\end{array}$ & 133 & $28.4^{\#}$ & 197 & $42.0^{\#}$ & 56 & 11.9 & 69 & 14.7 & 14 & 3.0 & $9.9(P=0.04)^{*}$ \\
\hline I do not think that blood donation is a religious duty & 18 & 3.8 & 51 & 10.9 & 82 & 17.5 & 159 & $33.9^{\#}$ & 159 & $33.9^{\#}$ & $57.48(P<0.00 \mathrm{I})^{*}$ \\
\hline I think that blood donation is a national duty & 209 & $44.6^{\#}$ & 178 & $38.0^{\#}$ & 38 & 82.0 & 27 & 5.8 & 17 & 3.6 & $28.6(P<0.00 \mathrm{I})^{*}$ \\
\hline $\begin{array}{l}\text { I would donate blood if there were incentives } \\
\text { or rewards }\end{array}$ & 12 & 2.6 & 14 & 3.0 & 8 & 1.7 & 155 & $33.0^{\#}$ & 280 & $59.7^{\#}$ & $5.45(P=0.244)$ \\
\hline $\begin{array}{l}\text { Donating blood makes me feel like I have helped } \\
\text { one of my family members or friends }\end{array}$ & 228 & $48.6^{\#}$ & 203 & $43.3^{\#}$ & 19 & 4.1 & 11 & 2.3 & 8 & 1.7 & II. $18(P=0.025)^{*}$ \\
\hline I would donate blood if given leave from work & 46 & 9.8 & 46 & 9.8 & 25 & 5.3 & 149 & $31.8^{\#}$ & 203 & $43.3^{\#}$ & $22.0(P<0.001)^{*}$ \\
\hline $\begin{array}{l}\text { A laboratory test performed on the donated blood } \\
\text { may help me to evaluate my health }\end{array}$ & 188 & $40.1^{\#}$ & 197 & $42.0^{\#}$ & 50 & 10.7 & 26 & 5.5 & 8 & 1.7 & $10.9(P=0.027)^{*}$ \\
\hline
\end{tabular}

Notes: "Positive attitude; *statistically significant. Sex differences were measured by the $\chi^{2}$ test.

Table 5 Knowledge and attitude percentage mean scores by some characteristics

\begin{tabular}{|c|c|c|}
\hline & $\begin{array}{l}\text { Knowledge percentage } \\
\text { score mean } \pm \text { SD }\end{array}$ & $\begin{array}{l}\text { Attitude percentage } \\
\text { score mean } \pm \text { SD }\end{array}$ \\
\hline \multicolumn{3}{|l|}{ Sex } \\
\hline Male & $56.89 \pm 16.95$ & $76.45 \pm 12.12$ \\
\hline \multirow[t]{3}{*}{ Female } & $61.79 \pm 16.80$ & $72.32 \pm 9.69$ \\
\hline & $t=2.68 ; P=0.008^{*}$ & $t=3.70 ; P<0.00 I^{*}$ \\
\hline & adj $P=0.098$ & $\operatorname{adj} P=0.00 I^{*}$ \\
\hline \multicolumn{3}{|l|}{ Age group } \\
\hline$<30$ years & $57.01 \pm 17.97$ & $75.71 \pm 12.42$ \\
\hline \multirow[t]{3}{*}{$\geq 30$ years } & $59.09 \pm 16.04$ & $75.21 \pm 10.99$ \\
\hline & $t=1.326 ; P=0.185$ & $t=0.46 ; P=0.644$ \\
\hline & adj $P=0.668$ & adj $P=0.312$ \\
\hline \multicolumn{3}{|l|}{ Education level } \\
\hline$\leq$ High school & $55.72 \pm 16.39$ & $75.86 \pm 11.23$ \\
\hline \multirow[t]{3}{*}{ University } & $60.90 \pm 17.38$ & $74.96 \pm 12.26$ \\
\hline & $t=3.321 ; P=0.00 I^{*}$ & $t=0.82 ; P=0.4 \mathrm{I}$ \\
\hline & $\operatorname{adj} P=0.00 I^{*}$ & adj $P=0.693$ \\
\hline \multicolumn{3}{|l|}{ Marital status } \\
\hline Married & $59.45 \pm 15.55$ & $75.48 \pm 11.30$ \\
\hline \multirow[t]{3}{*}{ Unmarried } & $56.10 \pm 18.80$ & $75.4 I \pm 12.28$ \\
\hline & $t=2.1 \mathrm{I} ; P=0.036^{*}$ & $t=0.06 ; P=0.952$ \\
\hline & adj $P=0.194$ & adj $P=0.457$ \\
\hline \multicolumn{3}{|c|}{ History of blood transfusion } \\
\hline Yes & $61.10 \pm 15.76$ & $76.20 \pm 11.82$ \\
\hline \multirow[t]{3}{*}{ No } & $56.43 \pm 17.48$ & $75.05 \pm 11.64$ \\
\hline & $t=2.86 ; P=0.004 *$ & $t=1.014 ; P=0.31 \mathrm{I}$ \\
\hline & adj $P=0.02 I^{*}$ & adj $P=0.112$ \\
\hline
\end{tabular}

Notes: Every variable was adjusted for all other variables in the table. *Statistically significant.

Abbreviations: adj, adjusted; SD, standard deviation.
(59.56\% versus $56.37 \% ; t=2.03 ; P=0.043)$ and higher PMS for attitude $(78.24 \%$ versus $72.27 \% ; t=5.75 ; P<0.001)$ than did those with no such history.

Table 6 shows the significant predictors of frequency for blood donation practice among the Saudi public. It shows that higher knowledge score $(t=2.59 ; P=0.01)$, higher attitude score ( $t=3.26 ; P=0.001)$, and male sex were all significant predictors of higher frequency of blood donation.

\section{Discussion}

The shortage of blood in most of the blood banks in different countries is due to the increase in demand with few people

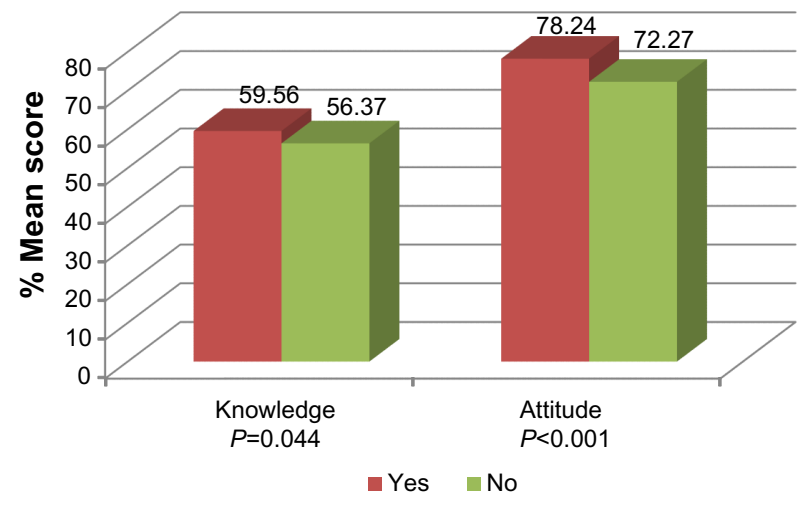

Figure 2 Percentage mean scores for knowledge and attitude towards blood donation by previous donation among the Saudi public.

Notes: "Yes" denotes previous blood donation and "No" denotes no previous donation. 
Table 6 Significant predictors for blood donation frequency among the Saudi public

\begin{tabular}{lllll}
\hline Independent variables & $\boldsymbol{\beta}$ & SE & $\boldsymbol{t}$ & $\boldsymbol{P}$ \\
\hline Sex (male =I) & 0.800 & 0.08 & 10.45 & $0.000^{*}$ \\
Age group & 0.037 & 0.08 & 0.45 & 0.652 \\
Married versus unmarried & 0.098 & 0.08 & 1.17 & 0.242 \\
$\begin{array}{l}\text { University versus High School } \\
\text { Total knowledge score }\end{array}$ & 0.070 & 0.06 & 1.10 & 0.274 \\
$\begin{array}{l}\text { percentage } \\
\text { Total attitude score }\end{array}$ & 0.005 & 0.002 & 2.59 & $0.010^{*}$ \\
$\begin{array}{l}\text { percentage } \\
\text { History of blood transfusion }\end{array}$ & -0.009 & 0.003 & 3.26 & $0.00 I^{*}$ \\
Constant & -0.927 & 0.06 & -1.58 & 0.115 \\
\hline
\end{tabular}

Note: *Statistically significant.

Abbreviation: SE, standard error.

coming to donate voluntarily. ${ }^{2}$ As non-remunerated donated blood is the only blood source in Saudi Arabia, people's motivation should be improved to keep the blood supply levels sufficient. Hence, more attempts should be made to attract society members for blood donation. ${ }^{25}$ In the present study, around half of the study sample reported a history of previous donation. Among the male subjects, $66 \%$ were previous blood donors, whereas among the females, only $13.3 \%$ were previous donors. This finding was similar to the finding of a study conducted in Iran, ${ }^{14}$ where $59.8 \%$ of males and $15.9 \%$ of females were previous donors. Of the 250 (35.3\%) donors, $235(94 \%)$ were males and only $15(6 \%)$ were females. This result is similar to what was observed in India, where $93 \%$ of donors were males and $7 \%$ were females. ${ }^{26}$

It has been reported that lack of time, and fear of complications are barriers to blood donation in both sexes. ${ }^{13}$ Time constraints may reflect the changing structure of society. In the current study, having no time was reported by more than half of male participants. This might be attributable to the Saudi culture, which obligates males to fully satisfy their families' needs and may lead to an inability to find free time to visit the donation centers. It has been noted that donors in the UK suffer significant out-of pocket costs, as well as lose of leisure time, and, in the economy more broadly, lost productivity. ${ }^{27}$

Practical problems and discomfort during donation were important reasons why women reported having stopped donation. ${ }^{9}$ Reducing women's discomfort during donation may therefore increase return rates. ${ }^{28,29}$ In the current study, two main reasons were reported by females. First was the inability to reach the donation centers, as reported by nearly half of female participants, which might be explained by the prohibition of females to drive in Saudi Arabia or the long distance to the donation centers. Second was the fear of becoming anemic, which was reported by more than one-third of females, although only $8 \%$ of them reported that donation may cause anemia. A study carried out among Dhaka University students in Bangladesh showed that only $16 \%$ of the donors ever donated voluntarily as physical harm and fear were found to be the common reasons for not donating. ${ }^{30} \mathrm{In}$ Granada, fears deterred 32.3\% from donating. ${ }^{31}$ The fear of becoming infected with HIV by donating blood was also a prevalent deterrent amongst the Scottish population, and this adversely affected their blood donation habit. ${ }^{32}$ In the current study, only $16 \%$ and $13 \%$ of female and male participants respectively reported fear of infection as a reason for not donating. Although the majority of participants reported that donation can cause transmission of infection to receivers, only $22 \%$ reported possible transmission to donor. This may explain why transmission of infection was not stated as a reason for not donating in the current study. Fear has been considered as the most commonly reported negative attitude on blood donation. ${ }^{2,13,14,18,21}$ In the current study, fear of the sight of blood was the reason for not donating in $6 \%$ and $11 \%$ of males and females, respectively.

Blood donor recruitment programs are required for the recruitment and retention of "safe" donors, and the proportion of repeat donors is an indicator of their success. This proportion is between $1 \%-70 \%$ (median $20 \%$ ) in the least developed countries and up to $85 \%$ (median $47 \%$ ) in developing countries, compared with values between $30 \%-90 \%$ (median $88 \%$ ) for developed countries. ${ }^{6}$ In the current study, $39.2 \%$ of those with history of previous donation were repeat donors of more than once, constituting half of male participants, a finding that is encouraging. Because the prevalence of markers for transmissible diseases is usually lower among repeat donors than among first time donors, ${ }^{33}$ an increased proportion of repeat donors is, in general, associated with decreased costs due to lower discard rates, as well as with improved blood safety. ${ }^{6}$

What makes an individual give blood? The factors influencing the individuals' decision to give blood are a collection of individual specific observable characteristics, such as sociodemographic factors, and unobservable characteristics, such as the degree of altruism. ${ }^{4}$ Studies have been carried out to examine how blood donors differ from non-donors with respect to their socioeconomic and demographic characteristics, such as sex, age, marital status, ethnicity, levels of education and income..$^{4,25,34,35} \mathrm{In}$ the current study, male sex and levels of knowledge and attitude on blood donation were the significant predictors of the frequency of donation. 
There is some evidence that suggests the more knowledge one has of the blood donation process and the need for blood increases, the more likely one is to donate blood. ${ }^{17,18}$ When knowledge PMS were compared between donors and non-donors, it was shown that donors had a significantly higher PMS of knowledge than non-donors. This is in agreement with a study by Dubey et al, where donors - specifically voluntary donors - had better knowledge than others..$^{36}$ This finding was evident after adjustment. However, his finding was not in agreement with another investigation administered to the students of Thai university that indicated that greater knowledge about blood donation does not necessarily lead to donation. ${ }^{37}$

It is clear that a lack of knowledge about blood donation or having false ideas will lead to a decrease in willingness to participate in blood donation. ${ }^{1}$ The present study showed in general, a poor level of knowledge about blood donation. The most commonly reported misconception in the current study was denying that blood donation can transmit an infection to the donor. A different result was observed in a study conducted in Nigeria, where $52.4 \%$ of donors believed that they could contact HIV and/or hepatitis infection from blood donation. ${ }^{3}$ Meanwhile, in a recent study, the risk of transmission of infectious and blood borne diseases was the reason that $40.4 \%$ of women were unwilling to donate blood. ${ }^{38}$ Another misconception was that women could not donate blood because of menstruation. Other studies reported loss of fertility and physical weakness as false beliefs about blood donation. ${ }^{36}$ Participants also had poor knowledge about the age limitation on blood donation and women's ability to donate with regard to menstruation. However, a study conducted in India showed that the majority of subjects knew about the minimum age to donate blood. ${ }^{26}$ In a study conducted in Saudi Arabia on 500 adult males, only 6\% of men were aware of the suitable age for blood donation while $28 \%$ knew about the minimum necessary weight. ${ }^{16}$

The decision to donate blood is influenced by some covariates such as altruism, social behavior, social pressure, and replacement. ${ }^{34,39}$ The highest motivational factor reported by the subjects in the current study was that donation gives a sensation of altruism, where almost all participants (96\%) agreed that donation is altruistic, agreeing with the Iranian population. ${ }^{13}$ Other studies reported personal or family benefits, financial rewards, and creating opportunities for donation as motivating factors to their donor populations. ${ }^{3,26}$ The majority of participants in the current study think that their donation would encourage others to donate. Although some findings indicate that using non-monetary incentives may help increase the number of lapsed blood donors, shifting to permanent incentives may make donors consider blood banks as a non-altruistic service. ${ }^{11}$ In the current study, the majority disagreed with donation if the donor is receiving leave from work or incentives. The majority agreed that donation is a national duty, and that when they donate blood they feel they are donating to a family member or a friend. Family discouragement was a reason for not donating for a few participants, yet the majority agreed that their families consider donation a valuable act and encourage them to donate. However, 34.1\% agreed that they would donate blood only if they were sure that the donation will be given to them or their family members in the future. More than half of participants considered donation a religious duty.

The level of knowledge was significantly predicted by university education and previous experience with blood transfusion in a family member. The more educated a person is, the more he knows about blood donation - this was observed in the current study as well as in the study in Iran. ${ }^{13}$ Education remained a significant predictor of knowledge level after adjusting for all possible confounders. The overall attitude of the studied subjects was neutral, with only $31.6 \%$ reporting a positive attitude to donation, a figure that reflects generally, an unfavorable attitude to donation, compared to $99 \%$ in a previous study by Abdel Gader et al..$^{21}$ This unfavorable attitude to donation in the present study may reflect the possible negative impact of an incident of HIV transmission to a young Saudi girl following blood transfusion ${ }^{24}$ on public perception to donation. Males had a better attitude than females, which is the opposite of what had been found in a similar study. ${ }^{13}$ Male sex was also a significant predictor of frequent blood donation in the present study, together with the higher attitude score to donation. Experience of prior blood donation, number of previous donations, and duration from last donation are correlated with future behavior. ${ }^{40-42}$ Individual attachment with someone who donates blood, or knowing people who have received donated blood all could influence willingness to donate blood. ${ }^{30,43,44} \mathrm{In}$ the current study, one-third of the study sample reported having someone in the family to whom blood was donated. This previous experience with blood transfusion was significantly associated with the level of knowledge of participants. The positive and direct relationship between attitude and awareness in this current study were similar to what has been reported by two studies conducted in Yazd, Iran. ${ }^{13,45}$

This study has some limitations. First, because the study was cross-sectional, a temporal relationship between exposure and outcome cannot be established. It is clear that the true causal relationships among all of the identified 
variables are complex and often reciprocal. For example, knowledge and attitude of the public on blood donation may be affected by previous donations. Second, the small number of females who participated in the study may not be representative of the whole female population in Saudi Arabia, and this would affect the generalizability of the results.

\section{Conclusion}

- Prevalence of blood donation was less than satisfactory among the Saudi public, probably due to misconceptions, poor knowledge and unfavorable attitudes to donation. An intensive campaign should be implemented to educate and encourage the public about blood donation to alleviate their fears and change their perceptions. The level of education of the donors, coupled with a positive attitude shown in the study, could be the driving factor in recruiting voluntary blood donors.

- Barriers to blood donations have to be thoroughly investigated. Qualitative surveys of blood donation may also provide a rich source of information on individuals' decisions to give blood. Adequate incentives in the form of honors, awards, or any other incentives that suit the community could be developed for these donors. It may also be useful to target men and women, perhaps by making donations easier for them by providing mobile blood collection nearer to individual's places of work and so reduce their time costs for donating.

\section{Acknowledgments}

This study was initiated and funded by the King Abdullah International Medical Research Center. This work was presented at the fifth Research Summer School program of the King Abdullah International Medical Research Center in July 2013.

\section{Disclosure}

The authors report no conflicts of interest in this work.

\section{References}

1. Safizadeh H, Pourdamghan N, Mohamadi B. University students awareness and attitude towards blood donation in Kerman City. Iranian Journal of Blood Cancer. 2009;1(3):107-110.

2. Karim MR, Alam M, Farazi MMR, Labone RJ. Factors influencing blood donation behavior of university level students in Bangladesh. Journal of Information Technology. 2012;1(1):35-40.

3. Olaiya MA, Alakija W, Ajala A, Olatunji RO. Knowledge, attitudes, beliefs and motivations towards blood donations among blood donors in Lagos, Nigeria. Transfus Med. 2004;14(1):13-17.

4. Hollingsworth B, Wildman J. What population factors influence the decision to donate blood? Transfus Med. 2004;14(1):9-12.
5. Politis C. Blood donation systems as an integral part of the health system. Archives of Hellenic Medicine. 2000;17(4):354-357.

6. Gibbs WN, Corcoran P. Blood safety in developing countries. Vox Sang. 1994;67(4):377-381.

7. Dhingra N, Lloyd SE, Fordham J, Amin NA. Challenges in global blood safety. World Hosp Health Serv. 2003;40(1):45-49.

8. World Health Organization. The Clinical Use of Blood in Medicine, Obstetrics Pediatrics, Surgery andAnesthesia, Trauma and Burns. Geneva: World Health Organization; 2001. Available from: http://apps.who.int/ medicinedocs/documents/s15413e/s15413e.pdf. Accessed July 1, 2014.

9. Misje AH, Bosnes V, Heier HE. Gender differences in presentation rates, deferrals and return behaviour among Norwegian blood donors. Vox Sang. 2010;98(3 Pt 1):e241-e248.

10. Mascaretti L, James V, Barbara J, et al. Comparative analysis of national regulations concerning blood safety across Europe. Trans Med. 2004;14(2):105-112.

11. Abolghasemi H, Hosseini-Divkalayi NS, Seighali F. Blood donor incentives: a step forward or backward. Asian J Transfus Sci. 2010;4(1): 9-13.

12. Gilcher RO, McCombs S. Seasonal blood shortages can be eliminated. Curr Opin Hematol. 2005;12(6):503-508.

13. Javadzadeh Shahshahani H, Yavari MT, Attar M, Ahmadiyeh MH. Knowledge, attitude and practice study about blood donation in the urban population of Yazd, Iran, 2004. Transfus Med. 2006;16(6): 403-409.

14. Mousavi F, Tavabi AA, Golestan B, et al. Knowledge, attitude and practice towards blood donation in Iranian population. Transfus Med. 2011;21(5):308-317.

15. Blood transfusions more than double since 1997 [webpage on the Internet]. Rockville, MD: Agency for Healthcare Research and Quality; 2009 [cited September 24, 2009]. Available from: http://archive.ahrq.gov/news/ newsroom/news-and-numbers/092409.html. Accessed July 1, 2014.

16. Alam M, Masalmeh Bel D. Knowledge, attitudes and practices regarding blood donation among the Saudi population. Saudi Med J. 2004;25(3):318-321.

17. Adam D, Soutar GN. A proposed model of the blood donation process. In: Cadeaux J, Uncles M, editors. Proceedings of the Australian and New Zealand Marketing Academy Conference, Sydney, Australia, 29 November-1 December 1999. Sydney: School of Marketing, University of New South Wales; 1999.

18. Wiwanitkit V. Knowledge about blood donation among a sample of Thai university students. Vox Sang. 2002;83(2):97-99.

19. Buciuniene I, Stoniene L, Blazeviciene A, Kazlauskaite R, Skudiene V. Blood donors' motivation and attitude to non-remunerated blood donation in Lithuania. BMC Public Health. 2006;6:166.

20. Godin G, Sheeran P, Conner M, et al. Factors explaining the intention to give blood among the general population. Vox Sang. 2005;89(3):140-149.

21. Abdel GaderAM, Osman AA, Al Gahtani FH, Farghali MN, RamadanAH, Al-Momen AM. Attitude to blood donation in Saudi Arabia. Asian $J$ Transfus Sci. 2011;5(2):121-126.

22. Sliwka D. Trust as a signal of a social norm and the hidden costs of incentive schemes. Am Econ Rev. 2007;97(3):999-1012.

23. Lownik E, Riley E, Konstenius T, Riley W, McCullough J. Knowledge, attitudes and practices surveys of blood donation in developing countries. Vox Sang. 2012;103(1):64-74.

24. Elwazer S, Jamjoom M, Ayish S. Saudi Health Ministry under fire in case of girl and alleged HIV-tainted blood [webpage on the Internet]. Atlanta, GA: CNN; 2013 [updated February 20, 2013]. Available from: http://edition.cnn.com/2013/02/20/world/meast/saudi-arabia-hiv-case/. Accessed October 19, 2013.

25. Nilsson Sojka B, Sojka P. The blood-donation experience: perceived physical, psychological and social impact of blood donation on the donor. Vox Sang. 2003;84(2):120-128.

26. Uma S, Arun R, Arumugam P. The knowledge, attitude and practice towards blood donation among voluntary blood donors in Chennai, India. J Clin Diagn Res. 2013;7(6):1043-1046. 
27. Varney SJ, Guest JF. The annual cost of blood transfusions in the UK. Transfus Med. 2003;13(4):205-218.

28. Ringwald J, Lange N, Rabe C, et al. Why do some apheresis donors donate blood just once. Vox Sang. 2007;93(4):354-362.

29. Newman BH, Newman DT, Ahmad R, Roth AJ. The effect of wholeblood donor adverse events on blood donor return rates. Transfusion. 2006;46(8):1374-1379.

30. Hosain GM, Anisuzzaman M, Begum A. Knowledge and attitude towards voluntary blood donation among Dhaka University students in Bangladesh. East Afr Med J. 1997;74(9):549-553.

31. Fernandez Montoya A, de Dios Luna del Castillo J, Lopez Berrio A, Rodriguez Fernandez A. [Attitudes, beliefs, and motivations in blood donors and non-donors]. Sangre (Barc). 1996;41(6):427-440. Spanish.

32. Robertson BJ, McQueen DV. Perceived risk of becoming infected with HIV by donating blood and changes in reported blood donation practice among the Scottish general public 1989-1992. AIDS Care. 1994;6(4):435-442.

33. Ward JW, Holmberg SD, Allen JR, et al. Transmission of human immunodeficiency virus (HIV) by blood transfusions screened as negative for HIV antibody. N Engl J Med. 1988;318(8):473-478.

34. Burnett JJ. Psychographic and demographic characteristics of blood donors. J Consum Res. 1981;8(1):62-66.

35. Burnett JJ, Leigh JH. Distinguishing characteristics of blood donor segments defined in terms of donation frequency. J Health Care Mark. 1986;6(2):38-48.
36. Dubey A, Sonker A, Chaurasia R, Chaudhary R. Knowledge, attitude and beliefs of people in North India regarding blood donation. Blood Transfus. 2014;12(Supp1 1):s21-s27.

37. Piliavin JA. Why do they give the gift of life? A review of research on blood donors since 1977. Transfusion. 1990;30(5):444-459.

38. Khadir M, Maghsoudlou M, Gharah Baghian A, et al. The evaluation of the attitude of Iranian women towards blood donation. The Scientific Journal of Iranian Blood Transfusion Organization. 2004;1(1): 27-34.

39. Oswalt RM, Hoff TE. The motivations of blood donors and nondonors: a community survey. Transfusion. 1975;15(1):68-72.

40. Flegel WA, Besenfelder W, Wagner FF. Predicting a donor's likelihood of donating within a preselected time interval. Transfus Med. 2000;10(3):181-192.

41. Whyte G. Quantitating donor behaviour to model the effect of changes in donor management on sufficiency in the blood service. Vox Sang. 1999;76(4):209-215.

42. Piliavin JA, Callero PL. Giving Blood: The Development of an Altruistic Identity. Baltimore, MD: Johns Hopkins University Press; 1999.

43. Lee L, Piliavin JA, Call VRA. Giving time, money, and blood: similarities and differences. Soc Psychol Q. 1999;62(3):276-290.

44. Schlumpf KS, Glynn SA, Schreiber GB, et al. L Factors influencing donor return. Transfusion. 2008;48(2):264-272.

45. Javadzadeh Shahshahani H. Knowledge, attitude and practice of women about blood donation. The Scientific Journal of Iranian Blood Transfusion Organization. 2006;3(3):213-220.
International Journal of General Medicine

\section{Publish your work in this journal}

The International Journal of General Medicine is an international, peer-reviewed open-access journal that focuses on general and internal medicine, pathogenesis, epidemiology, diagnosis, monitoring and treatment protocols. The journal is characterized by the rapid reporting of reviews, original research and clinical studies across all disease areas.

\section{Dovepress}

A key focus is the elucidation of disease processes and management protocols resulting in improved outcomes for the patient.The manuscript management system is completely online and includes a very quick and fair peer-review system. Visit http://www.dovepress.com/ testimonials.php to read real quotes from published authors. 